\title{
USO DE DISPOSITIVOS MÓVEIS EM EDUCAÇÃO ESCOLAR: O CELULAR COMO OBJETO DE ESTUDO NO ENSINO MÉDIO
}

\author{
Vitor Santos Nishizaki ${ }^{1}$ \\ Maria Cristina Marcelino Bento ${ }^{2}$
}

Resumo: O uso das Tecnologias da Informação e Comunicação Móveis e sem Fio (TIMS) aumentam os desafios da realidade escolar. Educadores precisam se adequar a realidade desenhada pelas TIMS. Entre as TIMS, temos o celular, um aparelho popular, com aplicativos que podem vir a ser utilizados em sala de aula como recurso pedagógico. Desta forma, a presente pesquisa busca responder: qual a visão de um grupo de professores do Ensino Médio em relação ao uso do celular em sala de aula? o objetivo da pesquisa é: apresentar possibilidades do uso do celular como recurso pedagógico para as aulas no Ensino Médio.

Palavras-chave: Celular; Dispositivos móveis; Ensino médio.

\footnotetext{
${ }^{1}$ Ensino Médio//EE Prof. Luiz de Castro Pinto, Brasil. E-mail: nishizaki.vitor@gmail.com.

2 Pedagogia/UNIFATEA, Brasil. E-mail: criscabento@gmail.com.
} 